\title{
Fostering Cross-Functional Skills And Attitudes In Business Administration Students
}

Mehenna Yakhou, (E-mail: mehenna.yakhou@gcsu.edu), Georgia College \& State University Vernon P. Dorweiler, Michigan Technological University

\begin{abstract}
This study presents the results of a descriptive survey mailed to 660 deans at schools of business in the U.S. to develop answers to the following research questions: 1. What integrative instructional methods are graduate business educators using at U.S. universities and colleges? 2. What teaching methods are most effective in fostering students' integrative skills and capabilities? 3. What is the level of difficulty for implementing these methodologies? 4. What are the implications for designing faculty reward systems and developing promotion and tenure criteria? Responses were received from 179 deans (27.12\% response rate). Findings reveal that other forms of integrating experience are practiced besides the more traditional capstone course. There is a wide spread agreement that inductive teaching methods are more effective in developing integrative skills and attitudes in students. However, these methods are believed to be the most difficult to implement in terms of time and effort. This suggests that adequate incentives must be in place to encourage faculty to adopt these methods. We hope that those schools contemplating revision and pedagogical development of faculty will find the study's findings timely and valuable.
\end{abstract}

\section{INTRODUCTION}

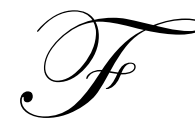

ollowing reports by Carnegie Council (Pierson, 1959) and the Ford Foundation (Gordon and Howell, 1959), business schools adopted the scientific model with the infusion of science into business education, shifting their focus from practice and application to more research and theory. In recent years, however, critics have argued the case for greater integration in the business education curriculum (Daniel and Pugh, 1975; Bain, 1992; Mutch, 1997; Boyd and Halford, 2001. Others have pointed out that business education has failed to keep up with the rapid changes in corporate business practices and in global market trends. One example is the report of the MIT Commission on Industrial Productivity by a team of academics and practitioners recommending the creation of a new cadre of students and faculty characterized by:

- $\quad$ Interest and knowledge of real problems and their societal, economic, and political context.

- $\quad$ An ability to function effectively as members of a team creating new products, processes, and systems.

- $\quad$ An ability to operate effectively beyond the confines of a single discipline.

- Integration of a deep understanding of science and technology with practical knowledge, a hands-on orientation, and experimental skills and insights. (emphasis added) : (Dertouzoz et al., 1989).

This research is built on the premise that corporate America needs business graduates with broad understanding of interconnections rather than focused specialists, more multidisciplinary knowledge rather than just a collection of specialized knowledge (Ijiri and Sunder, 1990). The ability to understand and integrate inputs from different areas is crucial to manage today's corporations.

As a result one of the important criteria of American Assembly of Collegiate Schools of Business (AACSB) accreditation of master of business administration (MBA) programs is the requirement that such programs incorporate 
an integrating experience in the curriculum (AACSB Guidelines, 1987-1988). Ottewill et al. (2005) also suggest that:

If integration is the goal of business education then attention should be given to creating a learning environment in which its virtues are clearly demonstrated and the vices of compartmentalization are eschewed.

The working definition of an integrating experience used for this study was the requirement that more than one functional business area or concern be addressed and balanced when making business decisions and solving realworld business problems.

Unlike previous research that examined teaching methods employed in specific courses (see for instance Feldmann, Dow, and Raghunandan, 1995; Daley, 1994), this study takes a broad perspective and builds on frameworks provided by Whetten and Clark (1996) and McCambridge and Thornton (1994) to address the issues of breaking down the functional mind-set in business administration students. Therefore, data were gathered to develop answers to the following questions:

- What integrative instructional methods are graduate business educators using at U.S. universities and colleges?

- What teaching methods are most effective in fostering students' integrative skills and capabilities?

- What is the level of difficulty for implementing these methodologies?

- What are the implications for designing faculty reward systems and developing promotion and tenure criteria?

\section{RESEARCH METHOD}

The survey instrument was addressed to 660 deans of business schools. The author felt that these individuals, as chief administrative officers of their respective schools, should have an excellent understanding of current curricula as well as insights into teaching methods used by various faculty members, as syllabi are readily available to them. Each subject was mailed a cover letter describing the study, a questionnaire and a postage-paid return envelope. The survey was designed to assess the various integrative teaching methodologies practiced at various U.S. business schools and to seek deans' opinions on the degree to which these various methods of instruction can help develop integrative skills and capabilities in students. The level of importance is reported on a Likert scale ranging from 1 (least important) to 5 (most important). Respondents were also requested to provide their opinion on the degree of difficulty of implementing these instructional methods. The level of difficulty is reported on a 5-point Likert scale with anchors ranging from 1 (least difficult) to 5 (most difficult). Fifteen teaching strategies were selected for inquiry based on a review of journal articles. The selection of the 15 teaching methods may not be exhaustive of all possible methods of teaching, and some of them might not be mutually exclusive as they might share certain common characteristics. A blank space was provided in the questionnaire and respondents were requested to list any additional teaching approaches.

\section{A FRAMEWORK FOR COMPARING TEACHING APPROACHES}

To effectively identify teaching approaches most likely to connect theory to its application in the work place and to foster integrative skills in students, this study uses the classification proposed in the educational literature to distinguish between two teaching pedagogy formats: (a) deductive (faculty informing-based) and (b) inductive (student discovery-based) teaching methods (Davis, 1993; Quinn et al., 1985; Boyatzis, Cowen, and Kolb, 1992).

In the faculty informing-based pedagogy format, the emphasis is on lectures, class discussions, and book assignments. The focus of this approach is passive learning, that is, students are presented with facts, rules, or principles and then they are asked to use these to explain and understand particular situations or experiences. In contrast, in student discovery-based pedagogy format, or action learning, students become active participants in the learning process, that is, they are involved directly in the activities they are studying whether the activities are real or part of a created environment (Whetten and Clark (1996). Dehler (1996) called for changing the teacher-centered oneway knowledge transfer to a learning-centered environment. 


\section{EXAMINING METHODS OF DELIVERY}

The various instructional methods considered in this study are briefly described below. The authors again realize that some of these techniques may not be mutually exclusive.

Faculty Informing (deductive/traditional) Methods:

Terminal Testing (exit comprehensive written exam, exit comprehensive oral exam, professional paper, thesis) is defined as [an] examination intended to measure the candidate's knowledge and/or his [her] ability to apply the information (Edwards \& Brannen, 1990). A test can also serves as a teaching method inasmuch as it telegraphs what is considered important about a given area or topic

Student Discovery (inductive/experiential/simulation-based) Methods:

With this approach, students perform activities from which they can derive conclusions about events. It can be a powerful tool to help students acquire a deeper understanding of concepts introduced in a course. Not only will students come to understand why events occur, they will also develop an understanding of how people react to them. In addition, this experiential approach is an excellent way to help students develop interpersonal skills. Research also suggests that because experiential learning requires full participation of the learner, students are likely to retain what they have learned (Van Eynd and Spenser, 1988). Within this category, activities can be real or part of a created environment. The teaching techniques included in the survey instrument falling under this category are presented below.

\section{Capstone Course}

The capstone course, most often titled Business Policy or Strategy, is a culminating educational experience for seniors, which attempts to integrate knowledge gained in all the functional business courses. As part of the requirements for this course, most often students are required to work in teams to perform an industry analysis using real data and extensive library research.

\section{Integrative Case Study Approach/Open-Ended Problems}

The case study approach involves diagnosis, analysis, and resolution of a particular problem in a constructed scenario. According to Majetka and Cossi (1981), the purpose of the case study is to aid learning, to think, to interact, and to function more professionally. The Harvard Business School on the other hand defines a case as the following [Christensen, 1987]:

A case is a partial, historical, clinical case study of a situation, which has confronted a practicing administrator or managerial group. Presented in a narrative form to encourage student involvement, it provides data-substantial and process-essential to an analysis of a specific situation for the framing of alternative action programs, and for their implementation recognizing the complexity of the practical world.

Likewise, open-ended problems refer to unstructured problems with minimal instructions.

- $\quad$ Projects Involving Students and Faculty from various Disciplines

- $\quad$ Team-Taught Courses, Issues Oriented Modules

The meaning of cross-functional integration in education is much broader that simply cross-disciplinary teaching. There is a trend toward more a cross-college collaboration. This may involve faculty from various disciplines cross-college working for instance on a project, specific issues, or team-teaching an interdisciplinary course. This pedagogical teaching format encourages faculty and students to take a broader perspective to learning by pursuing and applying integrative insights from two or more disciplines. Students and faculty develop an approach that helps them to clearly see the relationships among disciplines. That creates an environment for theoretical and 
applied learning. In such an environment the individuals involved assume more active roles. Dinmore (1997) pointed out that:

Team-teaching techniques are often, not surprisingly, a phenomenon of the interdisciplinary classroom. Instruction delivered by team- teaching, when implemented at anything beyond the most rudimentary levels, requires careful planning, integration of content, collaboration in classroom, and collaboration in the evaluation of student work and teacher performance...Modeling of shared power, and discussion of competing theories from different disciplines brings added value to the learner's classroom experience and can easily be extrapolated to situations outside the classroom.

\section{Computer Simulations}

Computer simulation is another pedagogical form that emphasizes active, inquiry-based learning. According to the dictionary definition, to simulate is to assume the appearance of characteristics of reality. In the context of organizations, simulation allows them to conduct what "if" experiments in decision processes. It's an effective means for putting the material being studied into a realistic, concrete, albeit, fictional- setting. Simulation games, roleplaying, are important means to develop student's decision-making ability, critical, inter-personal, cooperative, and integrative skills (Goodswell, Maher, and Tinto, 1992).

\section{Student Discovery (Inductive/Real-World-Based) Methods}

Research projects, internship, thesis internship programs, and student consulting teams are pedagogical forms that offer students the opportunity to apply to realistic settings the knowledge gained in the classroom in each subject area. The practical experience provided through these teaching methods can complement the students' experiential learning. They also present students with an opportunity to develop ties with employers for future long-term employment.

\section{RESULTS}

A total of 179 usable questionnaires were returned for a $27 \%$ return rate. Although $27 \%$ is a relatively low response rate, it was better than expected based on response rates reported in prior studies of a similar nature (cf., McCambridge and Thornton, 1994: 35\%; Morris et al., 1990: 23\%; Cargile and Bublitz, 1986: 24.8\%; Ketz and Kunilake 1985: 28\%).

Table 1 provides respondents' responses of which of those methods listed in the survey instrument are in use at their school. Six of the fifteen instructional methods considered in this study were widely used at the surveyed institutions: internships, capstone courses, team-based experiential activities, open-ended problem solving, and computer simulation game. Each of these six methods was used at least by 81 percent of the respondents. Approximately 98 percent of the responding schools offered internships. The popularity of internship programs demonstrates the value of internships to a student's educational experience. English and Koeppen (1993) indicated that:

- $\quad$ internships assignments made available to students earlier in their academic careers,

- $\quad$ can significantly and positively affect grade performance.

Their findings also support the contention that academic benefits of internships can be broader than coursespecific areas, such as providing opportunities to develop students' integrative skills. Students serving as team consultants to a client company, team-taught courses, projects involving students and faculty from various disciplines are also used at the surveyed schools but at a lesser extent. Other instructional methods less commonly used were exit comprehensive written and oral exams, theses, thesis internship programs, professional papers, and issues oriented modules. 
Table 1

Integrative Teaching Strategies in Use at U.S. Business Schools

$(\mathrm{N}=179)$

\begin{tabular}{lcc}
\hline Teaching Methods & \% & Rank \\
Internships & 98.0 & 1 \\
Capstone Course & 94.3 & 2 \\
Integrative Case Studies & 91.5 & 3 \\
Team-Based Experiential Activities & 88.0 & 4 \\
Open Ended Problem Solving & 81.3 & 5 \\
Computer Simulation Games & 80.6 & 6 \\
Students Serving as Team consultants to a Client Company & 68.9 & 7 \\
Team-Taught Courses & 53.1 & 8 \\
Project Involving Students and Faculty from Various Disciplines & 42.6 & 9 \\
Issue-Oriented Modules & 34.5 & 10 \\
Exit Comprehensive Written Exam & 26.1 & 11 \\
Professional Paper & 19.2 & 12 \\
Thesis Internship Program in Which Students Work on an & 10.9 & 13 \\
Inter-functional Project with a Corporation & 10.5 & 14 \\
Thesis & 3.5 & 15 \\
Exit Comprehensive Oral Exam & & \\
\hline
\end{tabular}

Table 2 provides information on the extent to which the various instructional strategies are important to foster integrative skills in students. The scale used was from 1 (least important) to 5 (most important). Within each area, the methods were sorted from most important to least important. Overall, the student discovering (inductive) real-world-based approach (overall mean of 3.71) and the student discovering (inductive/real-world-based) method (3.50) are the preferred forms of integrating experiences. The overall mean for the traditional, deductive pedagogical format was only 2.97.

Table 2

Mean Importance Scores and Rankings of Instructional Methods that Impart Integrative Skills and Attitudes

\begin{tabular}{llc}
\hline I. Deductive (Faculty Informing/Traditional) Methods: & Mean & Rank \\
1. Capstone course & 4.36 & 1 \\
2. Professional paper & 2.83 & 2 \\
3. Exit Comprehensive written Exam & 2.69 & 3 \\
4. Thesis & 2.50 & 4 \\
5. Exit Comprehensive Oral Exam & 2.46 & 5 \\
II. Inductive (Student Discovery/Experiential-Based) Methods: & 4.06 & 1 \\
1. Integrative Case Studies & 3.88 & 2 \\
2. Open-Ended Problems & 3.85 & 3 \\
3. Team-Based Experimental Activities & 3.60 & 4 \\
4. Projects Involving Students and Faculty from various Disciplines & 3.32 & 5 \\
5. Computer simulations games & 3.01 & 6 \\
6. Issues Oriented Modules & 2.80 & 7 \\
7. Team-taught Courses & & \\
III. Inductive (Student Discover/Real-World-Based) Methods: & 3.89 & 1 \\
1. Students Serving as Team Consultants to a Client Company & 3.78 & 2 \\
2. Internships & & \\
3. Thesis Internship Program in which Students & 3.46 & 3 \\
Work on an Inter-functional Project with Corporation & & \\
\hline
\end{tabular}




\section{Faculty Informing (Deductive/Traditional) Methods}

Teaching methods in the traditional category received little attention in the sampled institutions; and in the opinion of the respondents these methods are the least conducive to integrative skills in students with the exception of the capstone course, which received a high rating (mean of 4.36). This confirms Eward and Brannen' (1990) findings with regard to terminal testing methods. They concluded that terminal testing was used less frequently and that its use is declining, primarily because of the existence of the required business policy (capstone) course, making the terminal examination unnecessary. The present study also confirms that the capstone course seems to be the typical replacement for traditional testing methods.

\section{Student Discovery (Inductive/Experiential/Simulation-Based) Methods}

Overall this category was rated high (mean of 3.50). Four teaching strategies in this category received ratings of 3.60 or above. Considerably less importance is accorded to issues oriented modules and team-taught courses. It is interesting that such an instructional method as team-taught courses is thought less important in developing integrative skills in students.

\section{Student Discovery (Inductive/Real-World-Based) Methods}

This category (overall mean of 3.71) received the highest rating among the three teaching categories identified in the study. Many respondents have found that student discovery-real-world-based methods are an excellent way to develop integrative skills. The three instructional methods included in this category were rated 3.46 or above. Two of these methods are team based. As one might expect, the inclusion of these teaching approaches in business curricula will impress on students the solutions to problems from a system-wide perspective, and will serve to connect theory to its application in the work place.

\section{TEACHING METHODS AND DIFFICULTIES IN IMPLEMENTATION}

Program administrators might find information on implementation issues very useful in designing reward systems and developing promotion and tenure criteria. It appears that integrative teaching methods may require a greater time commitment and efforts by faculty when compared with traditional approaches. More traditional methods may not involve as much time or risk, as do less traditional methods. Respondents were asked in the survey to indicate the level of difficulty in terms of efforts and time in implementing each of the listed teaching methods. The average difficulty score and ranking for each of the methods are provided in Table 3 . The traditional methods are the least difficult to implement with an overall mean of 3.06. The respondents believe that the more innovative teaching methods are the hardest to implement. This might have implications for the design of incentive systems and promotion and tenure criteria.

For instance, Feldmann, Dowm and Raghunandan (1995) have examined the relationships between tenure status and pedagogical choices. They noted that untenured faculty might be less inclined to adopt new teaching methods than tenured faculty. They hypothesized that:

Incentive systems that favor research may lead new faculty to employ traditional teaching methods because this may require less preparation and grading time. In addition, nontraditional methods may increase the risk of negative student evaluations, which could discourage non-tenured faculty from attempting new approaches. On the other hand, tenured professors who have been successful with traditional approaches may have little incentive to adopt different styles. 
Table 3

Mean Implementation Difficulty Scores and Rankings of Instructional Methods that Impart Integrative Skills and Attitudes

\begin{tabular}{llc}
\hline I. Deductive (Faculty Informing/Traditional) Methods: & Mean & Rank \\
1. Exit Comprehensive Oral Exam & 3.61 & 1 \\
2. Thesis & 3.15 & 2 \\
3. Exit Comprehensive written Exam & 3.08 & 3 \\
4. Professional paper & 2.92 & 4 \\
5. Capstone course & 2.52 & 5 \\
1. Computer simulations games & 3.88 & 1 \\
2. Team-taught Courses & 3.87 & 2 \\
3. Projects Involving Students and Faculty from various Disciplines & 3.81 & 3 \\
4. Team-Based Experimental Activities & 3.08 & 4 \\
5. Issues Oriented Modules & 3.00 & 5 \\
6. Open-Ended Problems & 2.93 & 6 \\
7. Integrative Case Studies & 2.66 & 7 \\
1. Thesis Internship Program in which Students & & \\
Work on an Inter-functional Project with a Corporation & 3.82 \\
2. Students Serving as Team Consultants to a Client Company & 3.56 & 1 \\
3. Internships & 3.08 & 2 \\
\end{tabular}

They collected data about teaching methods used in the intermediate accounting course. They concluded nontenured faculty is just as likely as tenured to adopt nontraditional pedagogical styles. This is in contrast to Klein's conclusion (1990) with regard to interdisciplinary studies [IDS]. In effect, he concluded:

Research on career patterns supports the widely held belief that senior faculty are the most and perhaps the best suited for IDS activities. They are the ones who can risk time out of the disciplinary mainstream, and they are the ones who often need new challenges.

On the other hand, Newwell and Spear's (1993) study shows in some institutions IDS courses are dominated by younger scholars who are looking for creative pursuits (see also Payne, 1998). We strongly believe that institutions must design appropriate reward systems and develop clear promotion and tenure criteria that would motivate faculty to engage in more innovative teaching activities; otherwise, as Malekzadeh (1998) put it:

Faculty will be very reluctant to engage in curriculum revision knowing that the terrain is covered with mines and that the rewards are few.

\section{CONCLUSION}

Corporate leaders and academics alike have been stressing for quite some time the need, among other things, for business schools to strengthen student' integrative skills and capabilities. This study shows that business schools in the U.S. are moving toward more forms of integrating experience than the single capstone policy course that Porter and McKibbin (1988) referred to about a decade ago. Our study confirms prior research that teaching pedagogy is gradually changing from faculty informing to students discovering (Davis 1993; Quinn et al., 1990; Boyatzis, et al., 1992; Slater et al., 1995). This shifting in the way of teaching business education will certainly widen the students' range of study and increase their ability to operate effectively beyond the confines of a single discipline. Under the new forms of integrating experience, problem statements, based either on real or simulated data, are generally very brief, ambiguous, open ended, and ill defined, typical of how problems are encountered in real situations. Students are asked to use their combined multidisciplinary skills and knowledge to develop concepts and hypotheses about the proposals at hand. Since one is seldom presented with all the relevant data, students learn to seek out the information 
they feel they need for the problem. They may experience frustration by the inability to secure data they perceive they need. This lack of information is a potential growth experience in that the students must learn to make decisions using incomplete data.

The use of innovative instructional methods may reflect a fundamental shift in American Education. The present study’s findings support Saunder' (1997) views that this shifting is:

One that is replacing an older view of education as a place where students go to receive instruction, with a newer one as a place responsible for producing learning...The increasing use of cases and simulations [and other methods identified here] in business education indicates important changes in thinking and theory affecting our methods of instruction, the role instructors and students fulfill, and our expectations regarding learning outcomes.

\section{REFERENCES}

1. American Assembly of Collegiate Schools of Business (AAACSB). 1987/1988. Policies, Procedures, and Standards.

2. Bain, G.S., 1992.The future of management education. Journal of the Operational Research Society, Vol. 4(6):557-6.

3. Boyatzis, R., S. Cowen, and D. Kolb. 1992. Implementing Curricular Innovation in Higher Education: Year One of the New Weatherhead MBA Program. Selections (AACSB): 1-9.

4. Boyd, D. and Halford, J. 2001. Business education real time semester time?, International Journal of ValueBased Management, 14: 247-57.

5. Christensen, C. R., D. A. Garvin, and A. Sweet. (Eds.). 1991. Education for Judgment. Boston: Harvard Business School Press.

6. Cargile, B. and Bublitz. 1986. Factors contributing to published research by accounting faculties. The Accounting Review (January): 158-178.

7. Daley, M. Dennis. 1994. Teaching methods used in the personnel and human resources management general course- how public and business administration programs plant the seed of learning. Review of Public Personnel Administration, 14 (4): 39-51.

8. Daniel, W. and Pugh, H. (1975), Sandwich Courses in Higher Education, Political and Economic Planning, London.

9. Davis, J. R. 1993. Better Teaching, more Learning: Strategies for Success in Post-Secondary Settings. American Council on Education Series on Higher Education, Oryx Press, AZ.

10. Dehler, G. E. 1996. Management education as intentional learning: a knowledge-transforming approach to written composition. Journal of Management Education, 20(2): 221-235.

11. Dertouzoz, M. L., R. K. Lester, and R. M. Solow. 1989. Made in America: Regaining the Productivity Edge. Mass.: MIT Press.

12. Dinmore, Ian. 1997. Interdisciplinary and integrative learning: An imperative for adult education. Education, 117(3): 452-476.

13. Edwards, D. E. and D. E. Brannen. 1990. Current status of outcomes assessment at the MBA level. Journal of Education Business 65(5): 206-212.

14. English, M. Denise and David R. Koeppen. 1993. The relationship of accounting internships and subsequent academic performance. Issues in Accounting Education 8(2): 292-299

15. Feldamnn, Dorothy A., Kathy Dow, and K. Raghunandan. 1995. Tenure status and pedagogical choices. Journal of Education for Business, 7(1): 40-43.

16. Gordon, A. and J. E. Howell. 1959. Higher Education for Business. New York: Columbia University Press.

17. Goodswell A., M. Maher, and V. Tinto. 1992. Collaborative Learning: A Source Book for Higher Education. University Park, PA: National Center for Post secondary Teaching, Learning, and Assessment at Pensylvania State University.

18. Ijiri, Y. and S. Sunder. 1991. Realms and ideal of accounting education: Building Educational Leverage on Fundamentals, in Models of Accounting Education, edited by Gary L. Sunden and Corine T. Norgaard, Accouting Education Commission: 1-13. 
19. Ketz, J. and W. K. Kunitatke. 1985. Demand and supply for SEC courses. Journal of Accounting Education (Spring): 91-106.

20. Klein, J. T. 1990. Interdsciplinarity: History, Theory and Practice. Detroit: Michigan Wayne Stae University Press.

21. Malekzadeh, R. Ali. 1998. Diversity, Integration, globalization, and critical thinking in the upper division. Journal of Management Education. 22(5): 590-603.

22. Matejka, J. K. and T. J. Cossi. 1981. Case Method: An introduction. Reston, VA: Reston Publishing Co.

23. McCambridge J. and B. M. Thornton. 1994. A survey of institutional practices concerning the MBA integrating experience. Journal of Education for Business (January/February): 163-166.

24. Morris, J. L., M. Cudd, and J. L. Crain. 1990. The potential bias in accounting journal ratings: Evidence concerning journal-specific bias. Accounting Education Journal (Summer): 46-55.

25. Mutch, A. 1997. Rethinking undergraduate business education: a critical perspective. Management Learning, 28(3): 301-12.

26. Newwell, L. J. and K. T. Spear. 1983. New dimensions for academic careers: Recovering intrinsic satisfactions. Liberation Education, 69(2): 109-116.

27. Ottewill, R., G. McKenzie, and J. Leah. 2005. Integration and the hidden curriculum in business education. Education \& Training, 47(2/3): 89-97.

28. Payne, S. L. 1998. Interdisciplinary studies and management faculty involvement. Journal of Education for Business, 7(4): 211-214.

29. Pierson, R. C. 1959. The Education of American Businessmen. New York: McGraw-Hill.

30. Porter, L. W. and L. E. McKibben. 1988. Management Education and Development: Drift or Thrust into the 21st century. New York: McGraw-Hill Book Company.

31. Quinn, R. B., T. L. Doorley, and P. C. Paquette. 1995. Beyond products: services-based strategy. Harvard Business Review, July-August: 149-160.

32. Saunders, P. M. 1997. Experiential learning case, and simulations in business communication. Business Communication Quarterly (March): 97-114.

33. Slater, Jill Smith, Donald J. McCubbrey, and Richard A. Scudder. 1995. Inside an integrated MBA: An information system view. MIS Quarterly, 19(3): 391-410.

34. Van Eynde, D. E. And R. W. Spenser. 1998. Lectures versus experiential learning: Their differential effects on long-term memory. Organizational Behavior Teaching Review, 12(4): 52-58.

35. Whetten, A. and Sue Campbell Clark. 1996. An integrated model for teaching management skills. Journal of Management Education, 20(2): 152-181. 
NOTES 